\title{
Twin Pregnancy and Antenatal Examination: An Overview
}

\author{
Stamatios Petousis • Chrysoula Margioula-Siarkou • \\ Ioannis Kalogiannidis • Nikolaos Prapas
}

Published online: 24 August 2013

(C) Springer Science+Business Media New York 2013

\begin{abstract}
Total twinning rate has increased dramatically during the past 20 years, especially in Europe and the United States. This increase is mainly attributed to the widespread implementation of assisted reproductive techniques (ART). Twin gestation presents hazards at all ranges of gestational period, including risk for fetal wastage, fetal growth restriction, preterm labor, congenital abnormalities, twin-to-twin transfusion syndrome (TTTS) regarding monochorionic twins, and increased mortality rates. This review presents a summary of the appropriate antenatal examination strategy in twin pregnancies and, in parallel, emphasizes the main clinical problems that still pose controversies. Detection of chorionicity, measurement of nuchal translucency, fetal growth assessment based on twin-adjusted customized charts, structural anomaly scan, invasive procedures, non-stress test, biophysic profile, and MRI performance are the main issues analyzed. Finally, because twin gestations represent a challenging reality of modern obstetrics, this review also elucidates on the domains characterized by lack of evidence-based consensus, therefore raising the need for further research.
\end{abstract}

Keywords Twin pregnancy $\cdot$ High-risk gestation $\cdot$ Assisted reproductive techniques - Twin-to-twin transfusion - Prenatal medicine $\cdot$ Monochorionic twins $\cdot$ Antenatal examination

S. Petousis · C. Margioula-Siarkou • I. Kalogiannidis · N. Prapas 3rd Department of Obstetrics and Gynecology, Aristotle University of Thessaloniki, Thessaloniki, Greece

S. Petousis $(\square)$

Falireos 16, Evosmos, 56224 Thessaloniki, Greece

e-mail: petustam@mail.gr

\section{Introduction}

Rate of twin gestation currently varies between 1-2 \% of all pregnancies [1]. However, total twinning rate has increased dramatically during the past 20 years, especially in Europe and the United States [2-4]. This significant increase has been mainly attributed to the widespread implementation of assisted reproductive techniques (ART). It is estimated that $75 \%$ of the total increase of twin pregnancies' rate has been caused by ART methods; therefore, making a high-priority issue the reexamination of ART methods' policies regarding the optimal number of transferred embryos [5].

Twin gestation presents hazards at all ranges of gestational period [6]. Increased risk for fetal wastage, fetal growth restriction, preterm labor, congenital abnormalities, and mortality are only a part, yet important, of the range of complications associated with twin pregnancies [7-10]. Furthermore, in case of monochorionic twins, perinatal mortality is three to five times higher than in dichorionic ones [11]. Besides, twin-totwin transfusion syndrome (TTTS) will potentially develop in $10-15 \%$ of monochorionic gestations $[12,13]$. All the aforementioned aspects underline emphatically the need for effective, close, and mainly evidence-based surveillance, enrolling all available methods of antenatal examination. The main objective of the present review is to present an overview of the appropriate antenatal examination strategy in twin pregnancies and, in parallel, emphasize the main clinical problems that may pose dilemmas and controversies regarding their optimal diagnostic management.

\section{Detection of Chorionicity}

According to the guidelines of Royal College of Obstetricians and Gynaecologists, an ultrasound examination should be performed in all women with a diagnosed multiple pregnancy between 10-13 gestational weeks to assess viability and 
chorionicity (level II evidence) [14]. Relatively, French College of Gynaecologists and Obstetricians recommends the accurate diagnosis of chorionicity as early as possible in twin pregnancies, reporting that the most relevant signs are considered to be the number of gestational sacs between 7-10 gestational weeks and the "lambda sign" between 11-14 weeks [15••].

Lambda sign observation at 10-14 weeks has been widely implemented in the assessment of chorionicity. According to Sepulveda et al. [16], pregnancies should be classified as monochorionic in case a single placental mass is detected without lambda-sign observation at the inter-twin membrane-placental junction. In contrast, in case the signe placental mass co-exists with the lambda sign or placentas are not adjacent to each other, the diagnosis of a dichorionic pregnancy should be made. Antenatal sonographic prediction of chorionicity has been reported by Lee et al., in a retrospective series of 410 twins, to have specificity as well as positive and negative prognostic value greater than $90 \%$, while sensitivity was reported to be $89.8 \%$ [17].

Reliability of chorionicity assessment is highly depended on the operator's education and experience. Wesz et al. [18] in a cohort of 172 twins concluded that dichorionic-diamniotic chorionicity is determined accurately by sonographers rather than perinatologists at less than 14 weeks, whereas Devlieger et al. [19], in a retrospective follow-up of 87 consecutive twins observed that early detection of chorionicity and amnionicity is reliable by educated yet not highly experienced physicians.

An issue of high clinical interest is the optimal time of chorionicity assessment. As mentioned before, guidelines of RCOG and CNGOF conclude that chorionicity assessment should be performed between 10-13 gestational weeks. However, Bora et al. [20], in a retrospective analysis of prospectively collected data over a 3-year period, when comparing chorionicity diagnosis between 7-9 weeks' transvaginal and 11-14 weeks' transabdominal ultrasound examination, have observed a $98 \%$ rate of agreement between the two U/S observations regarding dichorionic-diamniotic cases, whereas the relative agreement rate was $100 \%$ for monoamniotic ones. However, chorionicity assessment by transvaginal ultrasound at 7-9 gestational weeks may not yet implemented as evidence-based diagnostic examination and, therefore, transabdominal ultrasound between 10-13 gestational weeks still presents the optimal antenatal diagnostic management.

\section{Nuchal Translucency}

Assessment of nuchal translucency (NT) should be performed by ultrasound examination between 10-13 weeks of gestation in all twin pregnancies for designation of risk for aneuploidy [21••]. CNGOF considers nuchal translucency as the best parameter to assess the risk for aneuploidy (level II) [14]. Canadian consensus guidilines [22] report that fetal nuchal translucency combined with maternal age should be considered an acceptable first trimester screening test for aneuploidies in twin pregnancies (II-2). Furthermore, because chorionicity has an outstanding impact on prenatal examination process, in dichorionic twins, there should be calculated a fetus-specific risk (II-3C) while in monoamniotic twins there should be provided a pregnancy-specific risk. Furthermore, apart from its contributive role in detecting chromosomal abnormalities, NT may contribute in the early diagnosis of TTTS in monoamniotic twins [23].

Several studies have indicated the high diagnostic significance of NT for detecting chromosomal abnormalities. Sepulveda et al., in a recent study recruiting 206 twin pregnancies, reported that NT thickness over 95th percentile has a sensitivity of $83.3 \%$ in diagnosing chromosomal abnormalities [24]. Besides, Monni et al., in a retrospective study that included 6,338 pregnancies, observed correlation between increased NT in multiple pregnancies and risk of chromosomal abnormalities [25]. Furthermore, several studies firmly underline that risk for Down syndrome according to NT should be estimated by using a fetus-specific risk algorithm. Maymon et al., when examining the between-fetus correlation coefficient of $\log$ NT in a series of 977 unaffected twins, reported that for a $3 \%$ false-positive rate, the model predicted detection rate was $68 \%$ in case between-fetus correlation was not taken into account, whereas it was increased to $73 \%$ when taken into consideration, finally concluding that a fetusspecific risk algorithm to detect Down syndrome may result in worthwhile increase in detection rates [26]. Relatively, Wright et al. [27] reported that correlation in NT measurements between the fetuses should be taken into consideration when estimating patient-specific risk.

Canadian consensus guidelines also mention that first trimester serum screening combined with NT additionally may improve prenatal diagnosis accuracy, because it may be characterized by decreased false-positive rates compared with the combination of NT and maternal age [22]. Prats et al., in a recently published study that included 227 twin pregnancies, compared three different prenatal screening strategies: NT screening, combined test screening, and combined test + ductus venosus pulsatility index (DVPI) [28•]. According to their results, NT screening false-positive rate was $10.9 \%$, whereas the relative rate for combined test was $6.2 \%(95 \%$ confidence interval (CI) 4.1-8.2 \%) with a $100 \%$ detection rate. A relative reduction also was observed by Madsen et al., who reported in a large series of 4,843 unaffected and 47 trisomy-21 twin pregnancies that adding biochemistry (PAPP-A and $\beta-\mathrm{HCG}$ ) in the algorithm resulted in improvement of false-positive rate from $8.0 \%$ to $5.9 \%$ [29]. Therefore, they concluded that enrollment of chorionicity-specific medians for biochemical markers in the risk assessment algorithm may additionally improve diagnostic accuracy and false-positive rates. 
NT measurement, apart from contributing in the detection of potential chromosomal abnormalities, also may contribute to the prediction of TTTS in monoamniotic cases. However, relative studies have presented controversial results in this field. Therefore, RCOG states that NT measurement's contribution in predicting TTTS is still unclear, with varying results of sensitivity and specificity. Indeed, Sperling et al. in a prospective study of more than 495 twin pregnancies reported that NT measurement was not helpful to predict TTTS [30]. However, Linskens et al. [23] have reported that NT discordance of more than $20 \%$ in 61 monochorionic monoamniotic twins has been significantly associated with subsequent development of TTTS. Relative results also have been mentioned by Kagan et al. [31], which mention that $30 \%$ of TTTS cases in monoamniotic twins have presented a discordance in NT measurement more than $20 \%$. Furthermore, there are recently published data that increased NT may be characterized by high specificity and positive prognostic value regarding other severe complications, such as fetal demise or preterm labor [32, 33•]. However, further research is needed before definitively enrolling NT measurement as predictive parameter for such outcomes in the routine antenatal examination algorithm.

In conclusion, NT measurement at 10-13 gestational weeks is highly recommended in all twin pregnancies to assess risk for chromosomal abnormalities. Combination with first trimester serum markers may significantly ameliorate false-positive rates, whereas there are firm indications that NT measurement may be contributive in the early detection of TTTS in monoamniotic cases as well as fetal demise and preterm labor. However, because of the existence of controversial results, there is still need for prospective, randomized trials to enroll NT measurement in the prediction of other complications.

\section{Fetal Growth}

Assessment of fetal growth is one of the most challenging issues regarding antenatal management of twin pregnancies. It is generally accepted that potential identification of fetal growth restriction may demand accurate fetal biometry as well as standardized fetal growth patterns [6]. Furthermore, antenatal examination algorithm definitely depends on the kind of pregnancy's chorionicity.

RCOG's guidelines underline that in monochorionic twin pregnancies, fetal ultrasound assessment should be performed every 2-3 weeks from 16 weeks regarding uncomplicated cases. This scanning should include at a minimum abdominal circumference, imaging of the fetal brain with or without head circumference, imaging of the fetal brain with or without head circumference measurement, femur length while measurement of amniotic pools' depth, and Doppler examination at
24 weeks also are recommended [14]. This examination is mainly focused on detection of Twin-to-Twin Transfusion syndrome (TTTS) between 16-24 weeks, whereas detection of potential growth restriction is set as the main purpose after 24 weeks. In any case, a close surveillance is demanded in monoamniotic cases, whereas in dichorionic-diamniotic twins, fetal growth scans may begin from 24 weeks and then be repeated at 28 weeks, 32 weeks, and two-to-four weekly, depending on each pregnancy's clinical condition.

Fetal growth surveillance in twins should be performed exclusively based on standardized growth charts for twins. Odibo et al. [34•], in a retrospective cohort that included 51,150 singletons and 1,608 twins, concluded that fetus classified as small for gestational age by twin-adjusted customized charts were indeed at significantly increased risk for intrauterine fetal death compared with those classified according to singleton-adjusted ones. According to Sankilampi et al. [35••], twins diverge from singletons from 30 gestational weeks onwards; at 37 gestational weeks birth weight is $400 \mathrm{~g}$ lower and mean birth length $1.2 \mathrm{~cm}$ shorter compared with singletons. The need to base fetal growth estimation on twinadjusted charts is further indicated by Danon et al. [36] who reported a higher mean percentage error in twins compared with singletons regarding fetal weight estimation. Therefore, as underlined by Gielen et al. [37], twin-specified growth charts, taking chorionicity into account are more accurate to detect twins at risk for neonatal death.

Because fetal growth discordance may have severe impacts on neonatal mortality and morbidity, it is highly important to define specific criteria of diagnosing fetal growth discordance. Crane et al. have proposed that fetal weight difference of more than $20 \%$ is significantly associated with increased risk for stillbirth [38]. Several published studies also are in accordance with the fact that estimated fetal growth difference greater than $20 \%$ is characterized by specificity, positive, and negative prognostic value greater than $90 \%$ with sensitivity ranging around $80 \%$, whereas no satisfying results have yet been mentioned when using other parameters of biophysical fetal profile, such as abdominal circumference or femur length [6]. However, evidence is not supportive of definite results regarding the optimal parameter and further research is needed (level II-2, level II-3).

All the aforementioned studies associate risk for fetal death with measurements of biophysical profile parameters after 24 gestational weeks. However, an interesting observation has been recently made by D' Antonio et al. [39••]. In their 10year retrospective study of more than 1,356 twin pregnancies, they observed that, regardless of chorionicity, early detection of CRL discordance even at 7-9 gestational weeks may be predictive of fetal loss diagnosed with the 11- to 14-week scan, presenting a high predictive accuracy (AUC $=0.93$, $95 \%$ CI 0.91-0.94). Despite the fact that updated guidelines emphasize the need for increased surveillance from 16 weeks 
in monoamniotic and from 24 weeks in dichorionic diamniotic cases, examination of CRL from first trimester may be indicative of growth discordance and, therefore, it should be given additional attention.

Doppler velocimetry of umbilical arteries also may be contributive in the detection of potential growth discordance. Joern et al. [40], in a study enrolling 206 twin pregnancies, have indicated that pathological findings of Doppler velocimetry were significantly associated with intrauterine growth retardation as well as risk for preterm delivery. Indeed, the median birth weight and the gestational age at birth were significantly lower in the group of twins with a pathological Doppler examination. Besides, abnormal systolic-diastolic ratios, when combined with estimated weight difference greater than $15 \%$, were indicated by Degani et al. [41] to have a sensitivity of $78 \%$ and specificity of $87 \%$ for detecting twin discordance. Doppler pathological waveforms seem to be of even higher importance in monochorionic twins especially in diagnosing arterio-arterial anastomoses with detection rates ranging from $75 \%$ to $85 \%$ according to Lemerle et al. [42]. Furthermore, Hack et al. conclude that abnormal Doppler flow of the umbilical artery may contribute to identifying monochorionic twins at increased risk for preterm delivery, low birth weight, and neonatal morbidity, especially at $>32$ weeks' gestation [43]. In conclusion, Doppler velocimetry of umbilical artery and especially systolicdiastolic ratio may provide additional indications regarding diagnosis of fetal growth discordance as well as risk for preterm delivery and neonatal morbidity, especially in monoamniotic twins. However, there is still no consensus on the exact manner that Doppler examination may be included in the antenatal examination of twin gestations and further research is demanded to achieve conclusions.

\section{Structural Anatomy Scan}

According to Consensus view from 50th Study Group of multiple pregnancies, twin pregnancies should undergo structure anatomy scan at 20-22 gestational weeks. Furthermore, structure anomaly scan should be accompanied by fetal echocardiography $[21 \bullet \cdot$. This also is stated by RCOG, which underlines that extended views of fetal heart should be included in the detailed second-trimester ultrasound scan (level of evidence II) and that a fetal echocardiographic assessment should be considered in assessing severe TTTS [14].

Predictive value of antepartum ultrasound examination in diagnosing congenital abnormalities has been outlined by several studies. Edwards et al. in a retrospective study of 245 consecutive twin gestations has reported a sensitivity of $88 \%$ with specificity of $100 \%$ [44]. In the same study, when adjusting for each individual anomaly, sensitivity was $82 \%$ while specificity $100 \%$, therefore indicating the high diagnostic significance of anomaly scan. Speling et al. [45], in a retrospective study enrolling 495 pregnancies, also reported that performance of anatomy scan after 19 gestational weeks and fetal echocardiography in week 21 resulted in high diagnostic rates of fetal and chromosomal abnormalities. However, it is essential to underline that structural anomaly scanning algorithm is primarily based on the first-trimester combined test, including serum markers and measurement of NT.

Regarding the necessity to perform fetal echocardiography in monoamniotic twins, there have been controversial results reported. According to Manning et al. [46], incidence of congenital heart defects is increased in monoamniotic twins, ranging at levels of $9-10 \%$, and therefore detailed fetal echocardiography in monoamniotic twins is justified. Relatively, $\mathrm{Ng}$ et al. have reported that monoamniotic twins have increased possibilities to present myocardial noncontraction [47]. Pettit et al. also report that $20 \%$ of infants with heart defects had TTTS versus $8 \%$ of infants without defects, therefore indicating a significant correlation between heart defects and TTTS [48]. However, Anderson et al., in a retrospective study of 30 pregnancies with TTTS, indicated that echocardiographic assessment of heart defects did not offer additional prognostic assistance [49]. Furthermore, Sperling et al., in a large Scandinavian study [50], also support the view that routine fetal echocardiographic examination is not justified. In conclusion, there is still no consensus on the fact that fetal echocardiography in monoamniotic twins may provide additional diagnostic contribution; however, there are strong indications in favor of performing fetal echo in monoamniotic cases, especially in those complicated by TTTS.

\section{Invasive Procedures}

Genetic Committee of the Society of Obstetricians and Gynaecologists of Canada along with Prenatal Diagnosis Committee of the Canadian College of Medical Genetics have presented thorough guidelines regarding invasive procedures performed to diagnose aneuploidies in twin pregnancies. First of all, it is recommended that, independent of age, the option of informed counseling process should be offered to all women (level I-A evidence). Furthermore, they also state that maternal age on its own should be considered as indication only if there are no noninvasive prenatal screening methods available (level II-2B evidence) [22].

Amniocentesis and chorionic villus sampling are the two basic options for prenatal invasive diagnostic procedures. Risk for fetal loss may present the main concern in such cases. Vink et al., in a systematic review of literature regarding amniocentesis in twin pregnancies, have demonstrated a pooled amniocentesis-related loss rate of $3.5 \%$ in twin gestation $<24$ weeks [51•]. However, Luis-Cordoba et al., in a recent 
prospective, observational study of amniocenteses performed over a 10-year period, report comparable rates of fetal loss between twins and singleton pregnancies (1.2\% vs. $1.1 \%)$ [52]. Relatively, Kalogiannidis et al. [53], in a retrospective study that included 6,270 pregnancies, report that incidence of adverse outcomes is not increased in diamniotic twins compared with singletons. Regarding pregnancy loss after chorionic villus sampling, Agarnal et al., in a systematic review recently published, report comparable pregnancy loss rates for CVS and amniocenteses [54]. However, further studies are needed to provide accurate definition of amniocentesis-related pregnancy loss rates for twin gestations and therefore be able to improve counseling for invasive procedures.

\section{Non-stress Test, Biophysic Profile, and Magnetic Resonance Imaging}

Non-stress test represents an examination for which limited data have been reported regarding their diagnostic contribution in twin pregnancies. The hypothesis that contraction stress tests may provide a factor potentially inducing increased uterine activity has not yet been scientifically supported, therefore, no contradictions to perform NST in twin pregnancies exist [6].

Reactive NSTs have been associated with good prognosis, including no perinatal mortality and growth restriction rates lower than $30 \%$, whereas nonreactive NSTs were correlated with increased rates of both aforementioned aspects $[6,55]$. In any case, there is lack of evidence concerning the diagnostic significance of NSTs in twins (level II-2 and II-3) with the indications, however, favoring the view that NST in twins may present similar screening performance to that observed in singleton pregnancies.

Similar to NST, biophysical profile testing has not yet been thoroughly examined. Lodeiro et al. [56], in a study examining BPP in 49 twins from 26 gestational weeks reported that BPP score $\geq 8$ was significantly associated with reactive NST and favorable outcome. Despite the initially encouraging results regarding BPP diagnostic contribution in twin pregnancies, further research should be performed to achieve safer conclusions.

Finally, the potential usage of magnetic resonance imaging (MRI) should not be omitted. Bekiesinska-Figatowska et al., in a recent study that included 17 cases of twin pregnancies compared MRI examinations between 19 and 39 gestational weeks with ultrasound findings. According to their results, MRI was superior to ultrasound in $64.7 \%$ of examined cases, whereas in the rest $35.3 \%$ MRI confirmed initial diagnosis [57]. Similar results are outlined by Perrone et al. [58] who reported that in a series of 128 patients, MRI confirmed the US diagnosis in the majority of cases, whereas there were anatomic anomalies identified by MRI that had not been diagnosed by MRI. Hoffmann et al. also have demonstrated that early manifestation of cerebral ischemia in monoamniotic twins complicated by intrauterine fetal demise was better diagnosed by MRI imaging [59]. Review of the literature may exclusively yield references standing in favor of MRI's diagnostic contribution and, therefore, further research should be performed to enroll MRI more actively in the antenatal examination algorithm of twin pregnancies.

\section{Special Issues: Gestational Diabetes and Preeclampsia in Twin Gestations}

Gestational diabetes mellitus (GDM) represents one of the most common complications during pregnancy, with an incidence ranging between 2-3\% [60]. Despite the controversies remarked regarding the potential existence of increased risk at twin pregnancy [61, 62], it is a fact that GDM and twin pregnancies share several common risk factors, such as advanced maternal age, marked weight gain throughout gestation, and an increased frequency of maternal obesity [60]. Furthermore, increased levels of gestagens, estrogens, and human placental lactogen in twin pregnancy may increase the risk of gestational diabetes because of their antagonists actions to insulin [63]. In any case, the coexistence of GDM in a twin gestation may cause several antenatal and perinatal hazards, including macrosomia, preterm labor, respiratory distress syndrome, preterm delivery, or even perinatal death [64, 65].

Antenatal diagnostic management of GDM in twin pregnancy is an issue characterized by further need for research. Yogev et al. [66] in a recent retrospective study of 14,797 pregnancies complicated by gestational diabetes compared the performance of the screening test for gestational diabetes in twin versus singleton pregnancies and concluded that $50-\mathrm{g}$ glucose tolerance test appears to be associated with a higher false-positive rate and a lower positive predictive value in twin pregnancies. Furthermore, as macrosomia presents an additional risk for twin fetuses in cases of GDM, increased surveillance regarding fetal growth is demanded, considering the fact that, according to Klein et al. [67], twin pregnancies with insulin-requiring gestational diabetes seem to have less birth weight discrepancy than twin pregnancies with normal glucose tolerance. In addition, the Polish Gynaecological Society recommends ultrasound assessment of fetal growth to be performed within 7 days before delivery to estimate the potential risk for shoulder dystocia in case of vaginal delivery [68]. The aforementioned studies are indicative of the fact that further research should be performed regarding the issue of optimal screening examination and fetal growth assessment. In any case, the need to establish a universal screening of GDM is predominant and twin gestations should have their priority in this particular field of interest [69].

Preeclampsia is another antenatal complication that is generally reported to be significantly associated with twin 
pregnancy. High pre-pregnancy body mass index, gestational diabetes, and egg donation have been remarked to be an independent prognostic factor for preeclampsia [70]. Preeclampsia is correlated with a variety of other antenatal outcomes with placental complications; praevia, abruption, and low birth weight gestations are the predominant ones [71].

An interesting issue is the impact that twin chorionicity may have on the occurrence of preeclampsia. Sparks et al. in a recent retrospective cohort of 695 pregnancies interestingly observed that dichorionic twin gestations are characterized by higher odds of developing mild preeclampsia compared with monochorionic twins, therefore, upraising the importance that chorionicity assessment has on management of twin gestations [72]. Furthermore, the diagnostic contribution of Doppler for early detection of preeclampsia also should be outlined. Klein et al. [73] in a screening study of more than 400 twins concluded that increased mean, lowest, and highest PI is associated with a higher risk of preeclampsia and adverse pregnancy outcome in twins along with observing the highest sensitivity and specificity by using highest PI. Finally, the wide range of potential biomarkers studied in the complex of preeclampsia's early detection, such as placenta protein 13 , cell free expression of hif $1 \alpha$, and p21 also should be mentioned $[74,75]$. Besides, the interest recently upraised regarding the first-trimester metabolomic detection of late-onset preeclampsia may potentially lead to innovations permitting the implementation of screening examination for the early detection and therefore treatment of hypertensive disorders in twin pregnancies [76••].

In conclusion, gestational diabetes and preeclampsia represent disorders that frequently complicate twin gestations. Increased risk for several antenatal complications necessitates the performance of further research in an effort to ameliorate antenatal examination strategy.

\section{Conclusions}

Antenatal examination of twin gestations involves a variety of diagnostic tools, each one of which has its differential role in the assessment of twins' health status. A relative layout of the basic examinations needed to be performed in every dichorionic twin gestation follows:

1. Ultrasound assessment of chorionicity, viability, and NT measurement at 10-13 gestational weeks

2. Measurement of maternal serum levels of PAPP-A and $\beta$-HCG (along with NT measurement) for aneuploidies' detection

3. Structural anomaly scan at 20-22 gestational weeks

4. Chorionic villus sampling (11-14 gestational weeks) or amniocentesis (18-22 gestational weeks) when karyotyping is necessitated
5. Serial fetal growth assessment scan at 24,28 , and 32 gestational weeks and then two-to-four weekly using twin-adjusted customized charts

6. Additional performance of NST and biophysic profile in selected cases

7. MRI additionally to $\mathrm{U} / \mathrm{S}$ especially in cases of anatomical structural abnormalities

Optimal management of monochorionic twins may be differentiated at two aspects:

a. Fetal echocardiography may be contributive along with structural anomaly scan at 20-22 gestational weeks

b. Ultrasound surveillance should begin at 16 gestational weeks for TTTS and then every 2 weeks, while fetal growth scan should be repeated at an equal frequency

Finally, it is a fact that twin gestations represent a challenging reality of modern obstetrics, especially in the era of assisted reproduction. Because a significant proportion of twin gestations are associated with the implementation of assisted reproduction techniques and therefore couple encounters additional stress to reassure pregnancy's wellbeing, it is essential to perform research in domains characterized by lack of evidence-based consensus as well as enhance optimal diagnostic algorithm implementation both in developed and developing countries.

\section{Compliance with Ethics Guidelines}

Conflict of Interest Stamatios Petousis, Chrysoula Margioula-Siarkou, Ioannis Kalogiannidis, and Nikolaos Prapas declare that they have no conflict of interest.

Human and Animal Rights and Informed Consent This article does not contain any studies with human or animal subjects performed by any of the authors.

\section{References}

Papers of particular interest, published recently, have been highlighted as:

- Of importance

•. Of major importance

1. Sebire NJ, Souka A, Skentou H, Geerts L, Nicolaides KH. First trimester diagnosis of monoamniotic twin pregnancies. Ultrasound Obstet Gynecol. 2000;16:223-5.

2. Derom R, Orlebeke J, Eriksson A. Textbook of perinatal medicine. The epidemiology of multiple births. London: Parthenon Publishing; 1998.

3. Botting BJ, Davies IM, MacFarlane AJ. Recent trends in the incidence of multiple births and associated mortality. Arch Dis Child. 1987;62:941-50.

4. Hoekstra C, Zhao ZZ, Lambalk CB, et al. Dizygotic twinning. Hum Reprod Update. 2008;14:37-47. 
5. Jewell SE, Yip R. Increasing trend in plural births in the United States. Obstet Gynecol. 1995;85:229-32.

6. Devoe LD. Antenatal fetal assessment: multifetal gestation-an overview. Semin Perinatol. 2008;32:281-7.

7. Hawrylyshyn PA, Barkin M, Bemstein A, et al. Twin pregnancies-a continuing perinatal challenge. Obstet Gynecol. 1982;59:463-6.

8. Knuppel RA, Rattan PK, Serbo JC, et al. Intrauterine fetal death in twins after 32 weeks. Obstet Gynecol. 1985;65:172-5.

9. Gaziano EP, De Lia JE, Kuhlmann RS. Diamnionic monochorionic twin gestations: an overview. J Matern Fetal Med. 2000;9:89-96.

10. Leduc L, Takser L, Rinfret D. Persistence of adverse obstetric and neonatal outcomes in monochorionic twins after exclusion of disorders unique to monochorionic placentation. Am J Obstet Gynecol. 2005;193:1670-5.

11. Sherer DM. Adverse perinatal outcome of twin pregnancies according to chorionicity: review of the literature. Am J Perinatol. 2001;18:23-37.

12. Denbow ML, Cox P, Taylor M, Hammal DM, Fisk NM. Placental angioarchitecture in monochorionic twin pregnancies: relationship to fetal growth, fetofetal transfusion syndrome and pregnancy outcome. Am J Obstet Gynecol. 2000;182:417-26.

13. Lopriore E, Middeldorp JM, Sueters M, Vandenbussche FPHA, Walther FJ. Twin-to-twin transfusion syndrome: from placental anastomoses to long-term neurodevelopmental outcome. Curr Pediatr Rev. 2005;1:191-203.

14. Royal College of Obstetricians and Gynaecologists. Management of monochorionic twin pregnancy. Green-top guideline No.51. December 2008.

15. •- Vayssière C, Benoist G, Blondel B, et al. French College of Gynaecologists and Obstetricians. Twin pregnancies: guidelines for clinical practice from the French College of Gynaecologists and Obstetricians (CNGOF). Eur J Obstet Gynecol Reprod Biol. 2011;156:12-7. This article outlines the guidelines of CNGOF regarding antenatal examination strategy of twin pregnancies.

16. Sepulveda W, Sebire NJ, Hughes K, Odibo A, Nicolaides KH. The lambda sign at 10-14 weeks of gestation as a predictor of chorionicity in twin pregnancies. Ultrasound Obstet Gynecol. 1996;7:421-3.

17. Lee YM, Cleary-Goldman J, Thaker HM, Simpson LL. Antenatal sonographic prediction of twin chorionicity. Am J Obstet Gynecol. 2006;195:863-7.

18. Weisz B, Pandya P, Dave R, Jauniaux E. Scanning for chorionicity: comparison between sonographers and perinatologists. Prenat Diagn. 2005;25:835-8.

19. Devlieger RG, Demeyere T, Deprest JA, et al. Ultrasound determination of chorionicity in twin pregnancy: accuracy and operator experience. Twin Res. 2001;4:223-6.

20. Bora SA, Papageorghiou AT, Bottomley C, Kirk E, Bourne T. Reliability of transvaginal ultrasonography at 7-9 weeks' gestation in the determination of chorionicity and amnionicity in twin pregnancies. Ultrasound Obstet Gynecol. 2008;32:618-21.

21. • Multiple Pregnancy-study group statement. Consensus views arising from the 50th Study Group: Multiple Pregnancy. This article summarizes the Canadian Consensus regarding prenatal diagnosis of aneuploidy in twin pregnancies.

22. Audibert F, Gagnon A, Genetics Committee of the Society of Obstetricians and Gynaecologists of Canada, Prenatal Diagnosis Committee of the Canadian College of Medical Geneticists. Prenatal screening for and diagnosis of aneuploidy in twin pregnancies. J Obstet Gynaecol. 2011;33:754-67.

23. Linskens IH, de Mooij YM, Twisk JW, Kist WJ, Oepkes D, van Vugt JM. Discordance in nuchal translucency measurements in monochorionic diamniotic twins as predictor of twin-to-twin transfusion syndrome. Twin Res Hum Genet. 2009;12:605-10.

24. Sepulveda W, Wong AE, Casasbuenas A. Nuchal translucency and nasal bone in first-trimester ultrasound screening for aneuploidy in multiple pregnancies. Ultrasound Obstet Gynecol. 2009;33:152-6.
25. Monni G, Zoppi MA, Ibba RM, Putzolu M, Floris M. Nuchal translucency in multiple pregnancies. Croat Med J. 2000;41:266-9.

26. Maymon R, Rosen H, Baruchin O, Herman A, Cuckle H. Model predicted Down syndrome detection rates for nuchal translucency screening in twin pregnancies. Prenat Diagn. 2011;31:426-9.

27. Wright D, Syngelaki A, Staboulidou I, Cruz Jde J, Nicolaides KH. Screening for trisomies in dichorionic twins by measurement of fetal nuchal translucency thickness according to the mixture model. Prenat Diagn. 2011;31:16-21.

28. - Prats P, Rodríguez I, Comas C, Puerto BJ. Analysis of three different strategies in prenatal screening for Down's syndrome in twin pregnancies. Matern Fetal Neonatal Med. 2013 Apr 30. [Epub ahead of print]. According to study's results, combination of PAPP-A and b-HCG along with NT measurement is superior to NT measurement only to assess risk for Down syndrome.

29. Madsen HN, Ball S, Wright D, Tørring N, Petersen OB, Nicolaides $\mathrm{KH}$, et al. A reassessment of biochemical marker distributions in trisomy 21-affected and unaffected twin pregnancies in the first trimester. Ultrasound Obstet Gynecol. 2011;37:38-47.

30. Sperling L. Detection of chromosomal abnormalities, congenital abnormalities and transfusion syndrome in twins. Ultrasound Obstet Gynecol. 2007;29:517-26.

31. Kagan KO, Gazzoni A, Sepulveda-Gonzalez G, Sotiriadis A, Nicolaides KH. Discordance in nuchal translucency thickness in the prediction of severe twin-to-twin transfusion syndrome. Ultrasound Obstet Gynecol. 2007;29:527-32.

32. Casasbuenas A, Wong AE, Sepulveda W. Nuchal translucency thickness in monochorionic multiple pregnancies: value in predicting pregnancy outcome. J Ultrasound Med. 2008;27:363-9.

33. - Goncé A, Borrell A, Meler E, et al. Prevalence and perinatal outcome of dichorionic and monochorionic twins with nuchal translucency above the 99(th) percentile and normal karyotype. Ultrasound Obstet Gynecol. 2010;35:14-8. This study underlines that NT >99th percentile with a normal karyotype is significantly associated with advanced risk for fetal abnormalities.

34. - Odibo AO, Cahill AG, Goetzinger KR, Harper LM, Tuuli MG, Macones GA. Customized growth charts for twin gestations to optimize identification of small-for-gestational age fetuses at risk of intrauterine fetal death. Ultrasound Obstet Gynecol. 2013;41:637-42. This retrospective cohort indicates emphatically the need to enroll customized charts for twins to assess fetal growth disorders.

35. • Sankilampi U, Hannila ML, Saari A, Gissler M, Dunkel L. New population-based references for birth weight, length, and head circumference in singletons and twins from 23 to 43 gestation weeks. Ann Med. 2013 Jun 14. [Epub ahead of print]. This is a study of high clinical interest presenting population-based references for several biophysical parameters in twins.

36. Danon D, Melamed N, Bardin R, Meizner I. Accuracy of ultrasonographic fetal weight estimation in twin pregnancies. Obstet Gynecol. 2008;112:759-64.

37. Gielen M, Lindsey PJ, Derom C, et al. Twin-specific intrauterine 'growth' charts based on cross-sectional birthweight data. Twin Res Hum Genet. 2008;11:224-35.

38. Grane JP, Tomich PG, Kopta M. Ultrasomic growth pattern in normal and discordant twins. Obstet Gynecol. 1980;55:678-83.

39. •- D'Antonio F, Khalil A, Mantovani E, Thilaganathan B; on Behalf of the Southwest Thames Obstetric Research Collaborative (STORK). Embryonic growth discordance and early fetal loss: the STORK multiple pregnancy cohort and systematic review. Hum Reprod. $2013 \mathrm{Jul}$ 11. [Epub ahead of print]. This meta-analysis concludes that CRL discordance on $C R L<5$ th percentile may independently be associated with fetal loss in twin pregnancies.

40. Joern H, Rath W. Correlation of Doppler velocimetry findings in twin pregnancies including course of pregnancy and fetal outcome. Fetal Diagn Ther. 2000;15:160-4. 
41. Degani S, Gonen R, Shpiro I, et al. Doppler flow velocity waveforms in fetal surveillance of twins. J Ultrasound Med. 1992;11:537-41.

42. Lemerle S, Le Vaillant C, Dubreil C, Boog GJ. Doppler waveforms patterns of vascular anastomoses in monochorionic twin pregnancies. A report of three cases and review of the literature. Gynecol Obstet Biol Reprod (Paris). 2007;36:777-85. Epub 2007 Jul 5.

43. Hack KE, Kaandorp JJ, Derks JB, Elias SG, Pistorius L, Visser GH. The value of umbilical artery Doppler velocimetry in the antenatal surveillance of uncomplicated monochorionic twin pregnancies. Ultrasound Obstet Gynecol. 2008;31:662-8.

44. Edwards MS, Ellings JM, Newman RB, Menard MK. Predictive value of antepartum ultrasound examination for anomalies in twin gestations. Ultrasound Obstet Gynecol. 1995;6:43-9.

45. Sperling L, Kiil C, Larsen LU, et al. Detection of chromosomal abnormalities, congenital abnormalities and transfusion syndrome in twins. Ultrasound Obstet Gynecol. 2007;29:517-26.

46. Manning N, Archer N. A study to determine the incidence of structural congenital heart disease in monochorionic twins. Prenat Diagn. 2006;26:1062-4.

47. Ng D, Bouhlal Y, Ursell PC, Shieh JT. Monoamniotic monochorionic twins discordant for noncompaction cardiomyopathy. Am J Med Genet A. 2013;161:1339-44.

48. Pettit KE, Merchant M, Machin GA, Tacy TA, Norton ME. Congenital heart defects in a large, unselected cohort of monochorionic twins. J Perinatol. 2013;33:457-61.

49. Anderson BL, Sherman FS, Mancini F, Simhan HN. Fetal echocardiographic findings are not predictive of death in twin-to-twin transfusion syndrome. J Ultrasound Med. 2006;25:455-9.

50. Herberg U, Gross W, Bartmann P, Banek CS, Hecher K, Breuner J. Long term cardiac follow up of severe twin to twin transfusion syndrome after intrauterine laser coagulation. Heart. 2006;92:95-100.

51. • Vink J, Fuchs K, D'Alton ME. Amniocentesis in twin pregnancies: a systematic review of the literature. Prenat Diagn. 2012;32:409-16. This is a well-designed meta-analysis dealing with amniocentesisrelated outcomes' rates in twins $<24$ gestational weeks.

52. Lenis-Cordoba N, Sánchez MA, Bello-Muñoz JC, et al. Amniocentesis and the risk of second trimester fetal loss in twin pregnancies: results from a prospective observational study. J Matern Fetal Neonatal Med. 2013 May 7. [Epub ahead of print].

53. Kalogiannidis I, Petousis S, Prapa S, Dagklis T, Karkanaki A, Prapas $\mathrm{Y}$, et al. Amniocentesis-related adverse outcomes in diamniotic twins: is there a difference compared to singleton pregnancies? Eur J Obstet Gynecol Reprod Biol. 2011;155:23-6. Epub 2010 Dec 4.

54. Agarwal K, Alfirevic Z. Pregnancy loss after chorionic villus sampling and genetic amniocentesis in twin pregnancies: a systematic review. Ultrasound Obstet Gynecol. 2012;40:128-34.

55. Blake GD, Knuppel RA, Ingardia CJ, et al. Evaluation of nonstress fetal heart rate testing in multiple gestations. Obstet Gynecol. 1984;63:528-32.

56. Lodeiro JG, Vintzileos AM, Feinstein SJ, et al. Fetal biophysical profile in twin gestation. Obstet Gynecol. 1986;67:824.

57. Bekiesinska-Figatowska M, Herman-Sucharska I, RomaniukDoroszewska A, et al. Diagnostic problems in case of twin pregnancies: US vs. MRI study. J Perinat Med. 2013;11:1-7.

58. Perrone A, Savelli S, Maggi C, et al. Magnetic resonance imaging versus ultrasonography in fetal pathology. Radiol Med. 2008; 113:225-41.

59. Hoffmann C, Weisz B, Yinon Y, et al. Diffusion MRI findings in monochorionic twin pregnancies after intrauterine fetal death. AJNR Am J Neuroradiol. 2013;34:212-6.

60. Cho HJ, Shin JS, Yang JH, et al. Perinatal outcome in twin pregnancies complicated by gestational diabetes mellitus: a comparative study. J Korean Med Sci. 2006;21:457-9.
61. Rauh-Hain JA, Rana S, Tamez H, et al. Risk for developing gestational diabetes in women with twin pregnancies. J Matern Fetal Neonatal Med. 2009;22:293-9. doi:10.1080/1476705080266319.

62. Buhling KJ, Henrich W, Starr E, Lubke M, Bertram S, Siebert G, et al. Risk for gestational diabetes and hypertension for women with twin pregnancy compared to singleton pregnancy. Arch Gynecol Obstet. 2003;269:33-6. Epub 2003 Apr 2.

63. Spellacy WN, Buhi WC, Birk SA. Human placental lactogen levels in multiple pregnancies. Obstet Gynecol. 1978;52:210-2.

64. Simões T, Queirós A, Correia L, Rocha T, Dias E, Blickstein I. Gestational diabetes mellitus complicating twin pregnancies. J Perinat Med. 2011;39:437-40.

65. Luo ZC, Simonet F, Wei SQ, Xu H, Rey E, Fraser WD. Diabetes in pregnancy may differentially affect neonatal outcomes for twins and singletons. Diabet Med. 2011;28:1068-73. doi:10.1111/j.1464-5491. 2011.03366.x.

66. Yogev Y, Eisner M, Hiersch L, Hod M, Wiznitzer A, Melamed N. The performance of the screening test for gestational diabetes in twin versus singleton pregnancies. J Matern Fetal Neonatal Med. 2013 May 30. [Epub ahead of print].

67. Klein K, Mailath-Pokorny M, Leipold H, Krampl-Bettelheim E, Worda C. Influence of gestational diabetes mellitus on weight discrepancy in twin pregnancies. Twin Res Hum Genet. 2010;13:393-7. doi:10.1375/twin.13.4.393.

68. Wender-Ozegowska E, Bomba-Opoń D, Brazert J, et al. Recommendations of Polish Gynecological Society concerning perinatal care in obese pregnant women. Ginekol Pol. 2012;83:795-9 [in Polish].

69. Arora D, Arora R, Sangthong S, Leelaporn W, Sangratanathongchai J. Universal screening of gestational diabetes mellitus: prevalence and diagnostic value of clinical risk factors. J Med Assoc Thail. 2013;96:266-71.

70. Fox NS, Roman AS, Saltzman DH, Hourizadeh T, Hastings J, Rebarber A. Risk factors for preeclampsia in twin pregnancies. Am J Perinatol. 2013 Apr 16. [Epub ahead of print].

71. Lučovnik M, Tul N, Verdenik I, Novak Z, Blickstein I. Risk factors for preeclampsia in twin pregnancies: a population-based matched case-control study. J Perinat Med. 2012;40:379-82. doi:10.1515/ jpm-2011-0252.

72. Sparks TN, Cheng YW, Phan N, Caughey AB. Does risk of preeclampsia differ by twin chorionicity? J Matern Fetal Neonatal Med. 2013 Mar 25. [Epub ahead of print].

73. Klein K, Mailath-Pokorny M, Elhenicky M, Schmid M, Zeisler H, Worda C. Mean, lowest, and highest pulsatility index of the uterine artery and adverse pregnancy outcome in twin pregnancies. Am J Obstet Gynecol. 2011;205:549.e1-7. doi:10.1016/j.ajog.2011.06. 103. Epub 2011 Jul 13.

74. Svirsky R, Meiri H, Herzog A, Kivity V, Cuckle H, Maymon R. First trimester maternal serum placental protein 13 levels in singleton vs. twin pregnancies with and without severe pre-eclampsia. J Perinat Med. 2013;16:1-6. doi:10.1515/jpm-2013-0011 [Epub ahead of print].

75. Ashur-Fabian O, Yerushalmi GM, Mazaki-Tovi S, Steinberg DM, Goldshtein I, Yackobovitch-Gavan M, et al. Cell free expression of hif1 $\alpha$ and p21 in maternal peripheral blood as a marker for preeclampsia and fetal growth restriction. PLoS One. 2012;7:e37273. doi:10.1371/journal.pone.0037273. Epub 2012 May 16.

76. •• Bahado-Singh RO, Akolekar R, Mandal R, Dong E, Xia J, Kruger $\mathrm{M}$, et al. First-trimester metabolomic detection of lateonset preeclampsia. Am J Obstet Gynecol. 2013;208:58.e1-7. doi:10.1016/j.ajog.2012.11.003. Epub 2012 Nov 13. This study presents interesting and innovating results regarding metabolomic detection of late-onset preeclampsia. 